\title{
ОСОБЕННОСТИ ПРАВОВОГО РЕГУЛИРОВАНИЯ ТРУДА ЗАНЯТЫХ В СЕТИ ИНТЕРНЕТ В ПОЛЬШЕ
}

Аннотация: В данной статье рассматривается правовое регулирование Интернет-занятости в трудовом законодательстве Республики Польша. Предметом данного исследования выступают процессы формирования польского трудового права и особенности имплементации «Рамочного соглашения о телеработе» принятого в рамках Европейского союза. Несмотря на быстро растущчий интерес современных исследователей к новым формам занятости, в том числе и базирующихся на Интернет-технологиях, проработка зарубежного законодательства, а особенно польского, на данный момент недостаточна и требует пристального внимания исследователей. качестве методов данного исследования выступили анализ законодательной базы Польши и Европейского Союза, российской и зарубежной научной литературы. В рамках данной работы определены: особенности и степень имплементации «Рамочного соглашения о телеработе» в польское трудовое законодательство, в сравнении с некоторыми другими странами Европейского Союза; соотнесены понятийнье аппараты; определены базовые права и обязанности занятых в сети Интернет и их работодателей в Польше. Ключевые слова: Интернет-занятость, социальное партнёрство, телеработа, трудовое право Польши, фриланс, информационное общество, атипичная занятость, постиндустриальное общество, удалённая работа, надомная работа.

Abstract: This article reviews the legal regulation of telework in the labor legislation of the Republic of Poland. The subject of this research is the processes of establishment of Polish labor law and peculiarities of the implementation of the "Framework Agreement of Telework" passed by the European Union. Despite the rapidly growing interest of modern researches towards new forms of employment, including those based on Internet technologies, there is insufficient research of foreign legislation (especially Polish) and requires close attention of the scholars. Within the framework of this article the author makes the following determinations: peculiarities and level of implementation of the "Framework Agreement of Telework" into Polish labor legislation in comparison to some other member-states of the European Union; comparison of the conceptual apparatus; the basic rights and responsibilities of telework employees and their employers in Poland.

Keywords: Online employment, Social partnership, Telework, Polish labor law, Freelance, Information society, Atypical employment, Post-industrial society, Distance work, Work from home.

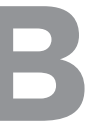

середине XX века произошли серьёзные изменения в социально-экономической структуре общества. Эти изменения были вызваны переходом индустриального общества в постиндустриальное, которое и стало определяющей социальной формой ХХ века в США, Японии и стран Западной Европе. К концу XX века определились черты нового постиндустриального общества, которые, по всей видимости, станут доминирующими характеристиками новой эпохи.

Глобальные процессы происходящие в политике, экономике, науке и технике затронули все сферы жизни современного общества и привели к серьёзным изменениям или возникновению абсолютно новых явлений.

С течением времени уровень жесткой иерархии и вертикальных связей в экономике снижается, соответственно происходят изменения критериев и способов найма и управления персоналом. Активное развитие и совершенствование Интернеттехнологий привело к образованию глобальной социально-экономической среды и формированию новых организационных и институциональных структур во всех сферах жизни общества ${ }^{1}$.

Развитие и распространение новейших информационно-коммуникативных технологий заметно меняет характер труда, структуру занятости населения, а также формы социально-трудовых отношений в современном обществе ${ }^{2}$. Стандартная занятость в настоящее время быстро утрачивает свою значимость и заменяется новыми, гибкими моделями труда ${ }^{3}$. В постиндустриальной экономике дистанционная занятость получила широкое

\footnotetext{
${ }^{1}$ Красильникова Е.В. Природа интернет-экономика // Известия Самарского университета. Серия: Экономика, управление, право. - 2010. Вып. 2. С. 10.

${ }^{2}$ Гимпельсон В., Капелюшников Р. Нестандартная занятость и российский рынок труда. Препринт WP3/2005/05. М.: ГУ ВШЭ. 2005. С. 7.

${ }^{3}$ Сизова, И.Л. Ищущие работу женщины на российском рынке труда // Женщина в российском обществе. 2013. №2. С. 41-42.
} 
распространение за счёт сети Интернет, которая выступает связующим звеном между работником и работодателем, и имеет различные социальные аспекты. С позиции работодателя это позволяет повысить производительность труда, существенно снизить издержки фирмы, найти и нанять сотрудников, обладающих узкоспециальными навыками и умениями ${ }^{4}$, а с другой - феномен занятости Интернет-занятости касается не только работодателя, но и самого Интернет-работника, оказывая на него целый ряд различных эффектов.

Под Интернет-занятостью или (телеработой, более распространённый термин в зарубежной литературе) следует понимать выполнение трудовой деятельности, которая раньше выполнялась на рабочем месте, а теперь с развитием Интернета стала возможна как надомная или мобильная 5 . Занятый в сети Интернет сам волен выбирать наиболее удобное для него место и время для выполнения своих трудовых обязанностей, если в трудовом соглашении не указано иного (например, в случае онлайн-консультирования, которое требует оказания услуг в удобное для клиентов время $\left.{ }^{6}\right)$, и основным критерием становится качественное и своевременное выполнение.

Особое место в исследовании социальных аспектов Интернет-занятости занимает рассмотрение законодательных норм регулирования этой формы занятости, а также ответственность сторон по отношению друг к другу. Данная работа ставит своей основной задачей проанализировать правовые нормы регулирования занятости в сети Интернет, с целью выявить трудовые права Интернет-работников, как особой категории нанимаемых сотрудников. В качестве объекта исследования избрано трудовое право Республики Польша, в котором уже на протяжении 7 лет существует

\footnotetext{
${ }^{4}$ Хусяинов T.M. Занятость в сети Интернет: позиция работодателя // Человеческие ресурсы в координатах XXI века: Сборник научных статей по материалам Международной научно-практической конференции, 27 ноября 2012 г. - Саратов: Издательство «КУБиК». 2012. С. 213-215.

${ }^{5}$ Хусяинов T.M. Занятость в сети Internet: позиция работника // Человек в мире. Мир в человеке: актуальные проблемы философии, социологии и политологи, психологии: Материалы XV Международной научно-практической конференции студентов, аспирантов и молодых учёных (29-30 ноября 2012 г.). Раздел II. Социологические и политологические исследования. - Пермь. 2012. С. $165-168$.

${ }^{6}$ Костригин А.А., Хусяинов Т.М. Онлайн-консультирование: организационные и психологические аспекты // Общество, семья, личность: теория и практика решения актуальных проблем: сб. науч. статей / под. ред. Ю.В. Брачиковой. Екатеринбург: Урал. гос. пед. ун-т. 2013. С. 84-88.
}

законодательное закрепление норм регулирующих Интернет-занятости в Трудовом Кодексе

Одной из объективных закономерностей в развитии современного права в странах Евросоюза, является углубление взаимодействия наднационального и национального права ${ }^{8}$, а юридическая ценность и эффективность европейских стандартов могут быть обеспечены их имплементацией в национальное право9. В контексте Европейской стратегии занятости, Европейский Совет предложил наиболее значимым организациям социального партнерства (представителям работников и работодателей) Европейского Союза заключить соглашение, направленное на модернизацию организации трудовой деятельности. Стоит упомянуть, что основными социальными партнерами в Европейском Союзе на сегодняшний день являются Европейская конфедерация профсоюзов (ETUC), Союз конфедераций промышленников и работодателей Европы (ранее UNICE, теперь BusinessEurope), Европейская ассоциация ремесленных, малых и средних предприятий (UEAPME), а также Европейский центр предприятий с участием государства и предприятий общего экономического интереса (CEEP).

Одним из важнейших документов современного европейского трудового права является «Implementation of the European framework agreement on telework» (Рамочное соглашение о телеработе), актуальность которого заключается в развитии и активном распространении новой атипичной формы занятости - телеработы (telework), иначе называемой занятость в сети Интернет, в современном мире, необходимостью регулирование которой и обусловлено заключение данного соглашения в июне 2002 г. между основными европейскими социальными партнёрами.

Особенность данного Соглашения состоит в том, что его имплентации не предшествовало при-

\footnotetext{
${ }^{7}$ Хусяинов T.M. Правовое регулирование занятости в сети Internet в Республике Польша // Право молодых (right of the young): Сборник трудов Всероссийской студенческой научной конференции (г. Ставрополь, 17-18 мая 2013 года). Ставрополь: Ставропольское издательство «Параграф». 2013. С. 210-213.

8 Дзыбова С.Г. Общие закономерности норм международного права в национальное законодательство // Вестник Адыгейского государственного университета. Серия 1: Регионоведение: философия, история, социология, юриспруденция, политология, культурология. 2010. №1. С.181.

9 Павлова, Л.В. Формы и методы имплементации стандартов Совета Европы в национальное законодательство. URL: http:// www.evolutio.info/content/view/1969/5/
} 
нятие соответствующей директивы ${ }^{10}$, вместо этого было предложено прямое внедрение в национальное право каждой из стран, исходя из специфики правового регулирования трудовых отношений. Преамбула данного Рамочного соглашения позволяет не только лишь частично имлементировать положения Соглашения, но и видоизменять их исходя из потребностей и специфики конкретного национального права.

В Республике Польша «Рамочное соглашение по телеработе» было реализовано в виде заключения двухстороннего соглашения между польскими социальными партнёрами,, крупные объединения работодателей и профсоюзные организации, среди которых были: Конфедерация польских работодателей, Конфедерация Левиафана (РКРP Lewiatan), организация «Солидарность», Польский альянс профсоюзов и Форум профсоюзов.

Польские социальные партнёры начали переговоры в январе 2005 г. и в ходе круглого стола по вопросам европейской социальной интеграции (OSDSIE) уже к 10 июня был достигнут консенсус, который вылился в подписание национального соглашения о телеработе. Этот текст содержится почти все положения Рамочного соглашения, а в некоторых случаях выходит за его пределы и более подробно рассматривает некоторые аспекты, что было необходимы для успешного принятия Соглашения всеми участниками. Но в дальнейшем данное Соглашение не было формально ратифицировано уставными органами организаций-участников, из-за отсутствия в проекте списка законодательных поправок, которые подписавшие стороны просили бы ввести. Тем не менее, неофициальные консультации продолжались, в том числе с правительством, темой этих консультаций был переход к законодательной стадии.

В 2006 г. Министерство труда и социальной политики, наконец, приняло Рамочное соглашение в качестве основы при разработке поправок для Трудового кодекса с целью создания правовой основы для удаленной работы. Проект закона был представлен социальным партнерам в октябре 2006 г. и обсуждались в рамках Трехсторонней комиссии по экономическим и социальным вопросам. Предложенные Правительством в апреле 2007 г. поправки, были приняты парламентом в августе и вступили в силу 15 октября, в результате чего в Трудовом Кодексе появилась

\footnotetext{
${ }^{10}$ Радевич E.P. Имплементация Рамочного соглашения о телеработе в странах Евросоюза // Правовые проблемы укрепления российской государственности: сб.статей / под ред. В.М. Лебедева, Г.Л. Осокиной, С.К. Соломина, В.С. Аракчеева, Н.Д. Титова. Томск: Изд-во Том. ун-та. 2013. Ч. 56. С. 124-126.
}

новая глава - IIb под названием «Найм работников в виде телеработы» (Zatrudnianie pracowników w formie telepracy) содержащая 13 новых статей (ст.67.5-67.17).

Польша избрала путь имплементации норм «Рамочного соглашения о телеработе» отличный от большинства других европейских стран: так в Италии ${ }^{11}$ и Бельгии ${ }^{12}$ был избран путь заключения национального соглашения о телеработе, на базе общеевропейского; во Франции при активном участии крупнейших компаний и профсоюзов государством были приняты 2 акта по регулированию Интернетзанятости в государственном и частном секторе ${ }^{13}$; в Румынии Интернет-занятость регулируется положениями Трудового кодекса о надомной работе ${ }^{14}$.

Новые положения фокусируются на специфике занятости в сети Интернет, в отношении ее внедрения и взаимоотношений между работодателем и работником. В вопросах, не регулируемых новой главы применяются положения Трудового Кодекса наравне с другими формами труда.

В соответствии с трудовым правом Польши, Интернет-работник (по-польски «Telepracownikiem») характеризуется тем, что выполняет работу за пределами компании и передаёт результаты своего труда по средствам электронных средств связи (в том числе по средствам сети Интернет). Особый порядок выполнения трудовых обязанностей приводит к необходимости определения правового положения работника нового типа.

К правам работника занятого в сети Интернет в соответствии с новыми положениями Трудового Кодекса Польши можно отнести:

- Добровольный характер перехода на Интернетзанятость. Ни один наёмный сотрудник в Польше не может быть принуждён работодателем отка-

${ }^{11}$ Хусяинов T.M. Правовое регулирование занятости в сети Интернет в Италии // Материалы Всероссийской научно-практической конференции «Правовая компетентность будущего педагога»: сборник научных статей. Выпуск 2 / под ред. М.В. Михайлова. Уфа: Изд-во БГПУ. 2013. С. 147-150.

${ }^{12}$ Хусяинов T.M. Регулирование занятости в сети Интернет в Бельгии: социальные и правовые аспекты // Актуальные проблемы права: Сборник материалов II Всероссийской научно-практической конференции с международным участием (6 декабря 2013 года). Махачкала: Издательский дом «Наука Плюс». 2013. С. 154-157.

${ }^{13}$ Хусяинов T.M. Правовое регулирование занятости в сети «Интернет» во Франции // Правовая система России: история и современность: материалы VI межвузовской (международной) научно-практической конференции. М.: Изд-во МГОУ. 2013. C. $356-360$.

${ }^{14}$ Хусяинов T.M. Особенности регулирования Интернет-занятости в Румынии // Актуальные проблемы современного законодательства. Сборник статей студентов, аспирантов, соискателей и преподавателей. М.: МФЮА. 2014. С. 627-633. 
заться от «стандартной» (офисной) занятости и перейти на удалённую форму работы, без своего на то согласие. С другой стороны работник может предложить подобный переход относительно себя, на что должен получить согласие работодателя (п. 3 ст. 67.7 ТК Польши);

- Участие в составлении трудовых соглашений в вопросах внедрения занятости в сети Интернет;

- Обеспечение со стороны работодателя всем необходимым оборудованием для выполнения трудовых обязанностей;

- $\quad$ Сохранение за Интернет-работником права доступа к инфраструктуре, оборудованию и помещениям, в которых работаю другие сотрудники организации, что очень важно для психологического здоровья ${ }^{15}$;

- Социальное и медицинское страхование наравне со «стандартными» работниками;

- $\quad$ Сохранение всех льгот и права на отпуск, которыми обладают «стандартные» работники;

- Право на неприкосновенность личной жизни, что особенно оговаривается относительно этой категории работников, т.к. их работа происходит за пределами помещений работодателя и требует особого контроля.

Отдельно стоит отметить, что в вопросах не регулируемых главой «Условия занятости удалённых работников» применяются общие положения Трудового Кодекса Польши наравне с другими формами трудовой деятельности.

Рассмотрение юридически закреплённых прав Интернет-работника позволит определить степень их социальной защищённости и в дальнейшем на законода- тельном уровне увеличить социальные гарантии и решать социальные проблемы, возникающие в ходе выполнения трудовых обязанностей подобными работниками.

В основном новый польский закон отражает «Рамочное соглашение...», в отношении определения телеработы, ее добровольный характер для обеих сторон и обратимость, равные условия трудоустройства, правила по оборудованию, право на неприкосновенность частной жизни, защиту здоровья и безопасности, и коллективные права, в отношении введения и практических деталей с представителями работников. В некоторых положениях польское законодательство выходит за рамки Рамочного соглашения, например, в отношении обязанностей работодателя при внедрении данной формы занятости.

Таким образом можно сделать вывод об особом механизме имплементации норм «Рамочного соглашения о телеработе» в польском трудовом праве, пути основанном прежде всего на законодательной инициативе, а не социальной солидарности как в странах Западной Европы, где роль законодателя минимальна и во многом выполняет утилитарную функцию лишь закрепляя положения общественного договора.

Изучение зарубежного опыта регулирования занятости в сети Интернет крайне важно для России. В Трудовом кодексе РФ первые изменения начали происходить только в октябре 2012 г. и продолжаются до сих пор ${ }^{16}$, а опыт и правоприменительная практика других стран может положительно сказаться на развитии законодательства, регулировании занятости в сети Интернет и правах Интернет-работников, а также позволит решить целый ряд социальных проблем возникающих у данной категории работников.

\section{Библиография:}

1. Гетьман-Павлова И.В. Коллизионное регулирование в международном частном трудовом праве // Вестник МГПУ. Серия: Юридические науки. 2008. №1. С. 107-114.

2. Демичева 3.Б. К вопросу о понятии «Правовые стандарты Совета Европы» // Москов. журн. междунар. права. 2006. № 3. С. 42-52.

3. Дзыбова С.Г. Общие закономерности норм международного права в национальное законодательство // Вестник Адыгейского государственного университета. Серия 1: Регионоведение: философия, история, социология, юриспруденция, политология, культурология. 2010. №1. С.180-185.

4. Красильникова Е.В. Природа интернет-экономика // Известия Самарского университета. Серия: Экономика, управление, право. 2010. Вып. 2. С. 9-14.

5. Лучинин А.Л. Особенности механизма имплементации европейского права: Дис. ... канд.юрид.наук.. Казань. 2006.177 с.

6. Гимпельсон В., Капелюшников Р. Нестандартная занятость и российский рынок труда. Препринт WP3/2005/05. M.: ГУ ВШЭ/ 2005. 36 с.

\footnotetext{
${ }^{15}$ Хусяинов T.M. Негативное влияние занятости в сети интернет на семейные отношения // Международная научно-практическая конференция: Социокультурные корни насилия в современном обществе. Н.Новгород: Издательство НИСОЦ. 2013. С. 466-468.
}

\begin{abstract}
${ }^{16}$ Хусяинов T.M. Заключение трудового соглашения между сотрудником занятым в сети Интернет и работодателем (социально-правовой анализ) // Право в современном мире: 20 лет Конституции РФ: материалы международной научно-практической конференции (молодежная секция). Екатеринбург, 6 декабря 2013 г. Екатеринбург: Уральский институт - филиал РАНХиГС. 2013. C. 405-408.
\end{abstract}


7. Павлова Л.В. Формы и методы имплементации стандартов Совета Европы в национальное законодательство. URL: http://www.evolutio.info/content/view/1969/5/ (обращение 10.10.2014).

8. Радевич Е.Р. Имплементация Рамочного соглашения о телеработе в странах Евросоюза // Правовые проблемы укрепления российской государственности: сб.статей / под ред. В.М. Лебедева, Г.Л. Осокиной, С.К. Соломина, В.С. Аракчеева, Н.Д. Титова. Томск: Изд-во Том. ун-та. 2013. Ч. 56. С. 124-126.

9. Сизова И.Л. Ищущие работу женщины на российском рынке труда // Женщина в российском обществе. 2013. №2. С. $41-42$.

10. Сизова И.Л. Регулирование трудовых отношений в социальном государстве // Социальное государство и инновационное развитие. Материалы научной конференции. М.: МГУ, 2010. С. 260-267.

11. Хусяинов T.M. Занятость в сети Internet: позиция работника // Человек в мире. Мир в человеке: актуальные проблемы философии, социологии и политологи, психологии: Материалы XV Международной научно-практической конференции студентов, аспирантов и молодых учёных (29-30 ноября 2012 г.). Раздел II. Социологические и политологические исследования. Пермь. - 2012. С. 165-168.

12. Хусяинов Т.М. Занятость в сети Интернет: позиция работодателя // Человеческие ресурсы в координатах XXI века: Сборник научных статей по материалам Международной научно-практической конференции, 27 ноября 2012 г. Саратов: Издательство «КУБиК». 2012. С. 213-215.

13. Хусяинов Т.М. Правовое регулирование занятости в сети Internet в Республике Польша // Право молодых (right of the young): Сборник трудов Всероссийской студенческой научной конференции (г. Ставрополь, 17-18 мая 2013 года). Ставрополь: Ставропольское издательство «Параграф». 2013. С. 210-213.

14. Хусяинов Т.М. Правовое регулирование занятости в сети Интернет в Италии // Материалы Всероссийской научнопрактической конференции «Правовая компетентность будущего педагога»: сборник научных статей. Выпуск 2 / под ред. М.В. Михайлова. Уфа: Изд-во БГПУ. 2013. С. 147-150.

15. Хусяинов Т.М. Особенности регулирования Интернет-занятости в Румынии // Актуальные проблемы современного законодательства. Сборник статей студентов, аспирантов, соискателей и преподавателей. М.: МФЮА. 2014. С. 627-633.

16. Хусяинов Т.М. Регулирование занятости в сети Интернет в Бельгии: социальные и правовые аспекты // Актуальные проблемы права: Сборник материалов II Всероссийской научно-практической конференции с международным участием (6 декабря 2013 года). Махачкала: Издательский дом «Наука Плюс». 2013. С. 154-157.

17. Хусяинов Т.М. Правовое регулирование занятости в сети «Интернет» во Франции // Правовая система России: история и современность: материалы VI межвузовской (международной) научно-практической конференции-М.: Изд-во МГОУ. 2013. С. 356-360.

18. Хусяинов Т.М. Заключение трудового соглашения между сотрудником занятым в сети Интернет и работодателем (социально-правовой анализ) // Право в современном мире: 20 лет Конституции РФ: материалы международной научно-практической конференции (молодежная секция). Екатеринбург, 6 декабря 2013 г. Екатеринбург: Уральский институт - филиал РАНХиГС, 2013. С. 405-408.

19. Шушкина В.В., Яворчук Н.Н. Телеработа и фриланс: в порядке постановки проблемы // Юридический вестник Кубанского государственного университета. 2010. № 5. С. 6-10.

20. European Foundation for the Improvement of Living and Working Conditions. 2010. URL: http://csdle.lex.unict.it/Archive/ LW/Data\%20reports\%20and\%20studies/Reports\%20and\%20studies\%20from\%20EUROFOUND/20110606-124753_ EUROFOUND_Telework_EU_Jan10pdf.pdf (обращение 10.10.2014).

21. Implementation of the European framework agreement on telework. Report by the European social partners on 28 JUNE 2006. - URL: http//www.etuc.org/a/579 (обращение 10.10.2014).

22. Report on the implementation of the European social partners «Framework Agreement on Telework» URL: http://ec.europa. eu/danmark/documents/alle_emner/beskaeftigelse/080702_arbejdstagere-3.pdf (обращение 10.10.2014).

23. Ustawa z dnia 26.06.1974 r. Kodeks pracy. URL: http://www.przepisy.gofin.pl/przepisy,2,18,33,212,,,ustawa-z-dnia-26061974r-kodeks-pracy.html (обращение 10.10.2014)

24. Шишкин В.В. Категория «Совместительство», ее сущность и соответствие общеправовым принципам правового регулирования // NB: Вопросы права и политики. - 2013. - 6. - С. 13 - 41. DOI: 10.7256/2305-9699.2013.6.804. URL: http://www.e-notabene.ru/lr/article_804.html

25. Касенова М.Б. Международное сотрудничество и управление использованием интернета // Международное право и международные организации / International Law and International Organizations. - 2014. - 1. -C. 6-15. DOI: 10.7256/2226-6305.2014.1.11411.

\section{References (transliterated):}

1. Get'man-Pavlova I.V. Kollizionnoe regulirovanie v mezhdunarodnom chastnom trudovom prave // Vestnik MGPU. Seriya: Yuridicheskie nauki. 2008. №1. S. 107-114.

2. Demicheva Z.B. K voprosu o ponyatii «Pravovye standarty Soveta Evropy» // Moskov. zhurn. mezhdunar. prava. 2006. № 3. S. 42-52.

3. Dzybova S.G. Obshchie zakonomernosti norm mezhdunarodnogo prava v natsional'noe zakonodatel'stvo // Vestnik Adygeiskogo gosudarstvennogo universiteta. Seriya 1: Regionovedenie: filosofiya, istoriya, sotsiologiya, yurisprudentsiya, politologiya, kul'turologiya. 2010. №1. S.180-185.

4. Krasil'nikova E.V. Priroda internet-ekonomika // Izvestiya Samarskogo universiteta. Seriya: Ekonomika, upravlenie, pravo. 2010. Vyp. 2. S. 9-14. 
5. Luchinin A.L. Osobennosti mekhanizma implementatsii evropeiskogo prava: Dis. ... kand.yurid.nauk.. Kazan'. 2006.177 s.

6. Gimpel'son V., Kapelyushnikov R. Nestandartnaya zanyatost' i rossiiskii rynok truda. Preprint WP3/2005/05. M.: GU VShE/ 2005. $36 \mathrm{~s}$.

7. Pavlova L.V. Formy i metody implementatsii standartov Soveta Evropy v natsional'noe zakonodatel'stvo. URL: http://www. evolutio.info/content/view/1969/5/ (obrashchenie 10.10.2014).

8. Radevich E.R. Implementatsiya Ramochnogo soglasheniya o telerabote v stranakh Evrosoyuza // Pravovye problemy ukrepleniya rossiiskoi gosudarstvennosti: sb.statei / pod red. V.M. Lebedeva, G.L. Osokinoi, S.K. Solomina, V.S. Arakcheeva, N.D. Titova. Tomsk: Izd-vo Tom. un-ta. 2013. Ch. 56. S. 124-126.

9. Sizova I.L. Ishchushchie rabotu zhenshchiny na rossiiskom rynke truda // Zhenshchina v rossiiskom obshchestve. 2013 . №2. S. 41-42.

10. Sizova I.L. Regulirovanie trudovykh otnoshenii v sotsial'nom gosudarstve // Sotsial'noe gosudarstvo i innovatsionnoe razvitie. Materialy nauchnoi konferentsii. M.: MGU, 2010. S. 260-267.

11. Khusyainov T.M. Zanyatost' v seti Internet: pozitsiya rabotnika // Chelovek v mire. Mir v cheloveke: aktual'nye problemy filosofii, sotsiologii i politologi, psikhologii: Materialy XV Mezhdunarodnoi nauchno-prakticheskoi konferentsii studentov, aspirantov i molodykh uchenykh (29-30 noyabrya 2012 g.). Razdel II. Sotsiologicheskie i politologicheskie issledovaniya. Perm'. - 2012. S. 165-168.

12. Khusyainov T.M. Zanyatost' v seti Internet: pozitsiya rabotodatelya // Chelovecheskie resursy v koordinatakh XXI veka: Sbornik nauchnykh statei po materialam Mezhdunarodnoi nauchno-prakticheskoi konferentsii, 27 noyabrya 2012 g. Saratov: Izdatel'stvo «KUBiK». 2012. S. 213-215.

13. Khusyainov T.M. Pravovoe regulirovanie zanyatosti v seti Internet v Respublike Pol'sha // Pravo molodykh (right of the young): Sbornik trudov Vserossiiskoi studencheskoi nauchnoi konferentsii (g. Stavropol', 17-18 maya 2013 goda). Stavropol': Stavropol'skoe izdatel'stvo «Paragraf». 2013. S. 210-213.

14. Khusyainov T.M. Pravovoe regulirovanie zanyatosti v seti Internet v Italii // Materialy Vserossiiskoi nauchnoprakticheskoi konferentsii "Pravovaya kompetentnost' budushchego pedagoga": sbornik nauchnykh statei. Vypusk 2 / pod red. M.V. Mikhailova. Ufa: Izd-vo BGPU. 2013. S. 147-150.

15. Khusyainov T.M. Osobennosti regulirovaniya Internet-zanyatosti v Rumynii // Aktual'nye problemy sovremennogo zakonodatel'stva. Sbornik statei studentov, aspirantov, soiskatelei i prepodavatelei. M.: MFYuA. 2014. S. 627-633.

16. Khusyainov T.M. Regulirovanie zanyatosti v seti Internet v Bel'gii: sotsial'nye i pravovye aspekty // Aktual'nye problemy prava: Sbornik materialov II Vserossiiskoi nauchno-prakticheskoi konferentsii s mezhdunarodnym uchastiem (6 dekabrya 2013 goda). Makhachkala: Izdatel'skii dom «Nauka Plyus». 2013. S. 154-157.

17. Khusyainov T.M. Pravovoe regulirovanie zanyatosti v seti «Internet» vo Frantsii // Pravovaya sistema Rossii: istoriya i sovremennost': materialy VI mezhvuzovskoi (mezhdunarodnoi) nauchno-prakticheskoi konferentsii-M.: Izd-vo MGOU. 2013. S. 356-360.

18. Khusyainov T.M. Zaklyuchenie trudovogo soglasheniya mezhdu sotrudnikom zanyatym v seti Internet i rabotodatelem (sotsial'no-pravovoi analiz) // Pravo v sovremennom mire: 20 let Konstitutsii RF: materialy mezhdunarodnoi nauchnoprakticheskoi konferentsii (molodezhnaya sektsiya). Ekaterinburg, 6 dekabrya 2013 g. Ekaterinburg: Ural'skii institut - filial RANKhiGS, 2013. S. 405-408.

19. Shushkina V.V., Yavorchuk N.N. Telerabota i frilans: v poryadke postanovki problemy // Yuridicheskii vestnik Kubanskogo gosudarstvennogo universiteta. 2010. № 5. S. 6-10.

20. Shishkin V.V. Kategoriya "Sovmestitel'stvo", ee sushchnost' i sootvetstvie obshchepravovym printsipam pravovogo regulirovaniya // NB: Voprosy prava i politiki. - 2013. - 6. - C. 13 - 41. DOI: 10.7256/2305-9699.2013.6.804. URL: http://www.enotabene.ru/lr/article_804.html

21. Kasenova M.B. Mezhdunarodnoe sotrudnichestvo i upravlenie ispol'zovaniem interneta // Mezhdunarodnoe pravo i mezhdunarodnye organizatsii / International Law and International Organizations. - 2014 - 1. - C. 6 - 15. DOI: 10.7256/22266305.2014.1.11411. 